\title{
Estudo da contribuição de um sistema de ar condicionado com distribuição de ar pelo piso para a remoção de particulados e dióxido de carbono do ar de um ambiente interno
}

\author{
Study on the contribution of an indoor underflow air \\ distribution system for the removal of particulates and \\ carbon dioxide from an indoor environment
}

\begin{tabular}{|c|c|}
\hline & $\begin{array}{l}\text { Renate Marè } \\
\text { Brenda Chaves Coelho Leite } \\
\text { Resumo }\end{array}$ \\
\hline & 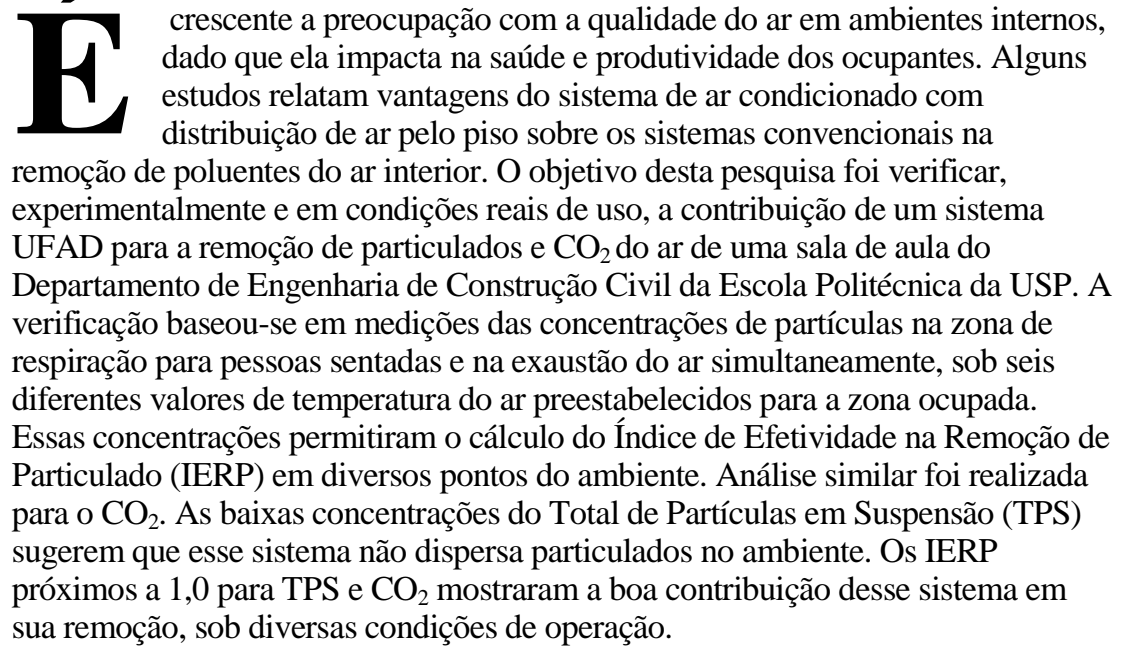 \\
\hline & $\begin{array}{l}\text { Palavras-chave: Sistema de ar condicionado com distribuição de ar pelo piso. } \\
\text { Remoção de poluentes. Ar interior. }\end{array}$ \\
\hline & $\begin{array}{l}\text { Abstract } \\
\text { Indoor air quality is a growing concern, since it impacts the health and } \\
\text { productivity of occupants of indoor areas. Some studies report on the benefits of } \\
\text { underfloor air distribution (UFAD) systems in removing indoor air pollutants, } \\
\text { when compared with overhead systems. The objective of this research study was to } \\
\text { verify experimentally and in a non-steady state condition, the contribution of an } \\
\text { UFAD system to the removal of particulates and } \mathrm{CO}_{2} \text { from the air of a classroom } \\
\text { located at the Construction Engineering Department of the Polytechnic School of } \\
\text { USP. This verification was based on simultaneous measurements of particle }\end{array}$ \\
\hline $\begin{array}{r}\text { Renate Marè } \\
\text { Universidade de São Paulo } \\
\text { São Paulo - SP - Brasil }\end{array}$ & $\begin{array}{l}\text { USP. This verification was based on simultaneous measurements of particle } \\
\text { concentrations in the breathing zone and at the air exhaust, under six different pre- } \\
\text { defined values of air temperature in the occupied zone. Those concentrations } \\
\text { enabled the calculation of the Particulate Removal Effectiveness index (PRE), at }\end{array}$ \\
\hline $\begin{array}{r}\text { Brenda Chaves Coelho Leite } \\
\text { Universidade de São Paulo } \\
\text { São Paulo - SP - Brasil }\end{array}$ & $\begin{array}{l}\text { various points distributed throughout the environment. A similar analysis was } \\
\text { performed for } \mathrm{CO}_{2} . \text { The low concentration levels of Total Suspension Particle } \\
\text { suggest that this system does not disperse air pollutants indoors. The PRE indexes } \\
\text { near 1.0, for both total suspension particle and } \mathrm{CO}_{2} \text {, confirmed the positive }\end{array}$ \\
\hline & contribution of this system to their removal, under different operational conditions. \\
\hline & Keywords: Underfloor air distribution system. Pollutant remova. Indoor air. \\
\hline
\end{tabular}

MARĖ, R.; LEITE, B. C. C. Estudo da contribuição de um sistema de ar condicionado com distribuição de ar pelo piso para a remocão de particulados e dióxido de carbono do ar de um ambiente interno. Ambiente Construído, Porto Alegre, v. 13, n. 4, p. 7-14, jul./set. 2013.

ISSN 1678-8621 Associação Nacional de Tecnologia do Ambiente Construído. 


\section{Introdução}

Existem inúmeras fontes de poluentes químicos e biológicos no ar interior (ABNT, 2008; AMERICAN..., 2004a; AGÊNCIA..., 2003). Podem ser citadas como fontes de material particulado infiltrações de áreas adjacentes, o próprio sistema de ar condicionado e as pessoas. Só a pele humana libera cerca de 1 bilhão de microfragmentos por dia. As pessoas também liberam gotículas, formando um aerossol que contém partículas que, misturando-se ao pó do chão e demais superfícies, podem incrementar a suspensão de particulado pelas correntes de ar do sistema de ar condicionado ou pelo movimento das pessoas (PEREIRA, 2008). Os sistemas de ar condicionado devem ter um importante papel na filtragem do ar externo e na renovação de ar dos ambientes internos, e assim proporcionar a redução da concentração dos poluentes a níveis aceitáveis (ABNT, 2008). A capacidade de um sistema de remover poluentes do ar interior pode ser avaliada pela relação entre a concentração de poluentes no ar ao nível da exaustão e a concentração de poluentes ao nível da zona de respiração (MUNDT et al., 2004). Para sistemas com distribuição de ar pelo piso, o índice resultante chega a 1,3 , o que é muito satisfatório, enquanto para sistemas convencionais com insuflamento de ar pelo teto, raramente ultrapassa 1,0 (CERMAK; MELIKOV, 2006). No sistema com distribuição de ar pelo piso, o ar condicionado é levado diretamente à zona ocupada por meio de um plenum inferior, e a exaustão do ar usualmente é feita por um plenum superior. No plenum inferior, uma considerável deposição de partículas pode ser encontrada, o que pode comprometer o desempenho do sistema em sua remoção, além de incrementar a suspensão de partículas no ambiente (MUNDT, 2001). Essas questões mostram a importância de estudos mais aprofundados sobre o sistema com distribuição de ar pelo piso (ABE; INATOMI; LEITE, 2006). No entanto, esse sistema apresenta inúmeras vantagens quando comparado ao sistema com insuflamento de ar pelo teto, tais como:

(a) melhor eficiência da distribuição de ar nas zonas de ventilação e percepção de elevada qualidade do ar interior (devido à estratificação da temperatura, convecção natural e suprimento de ar fresco diretamente na zona ocupada);

(b) uso reduzido de energia (o ar é insuflado a temperaturas mais elevadas); (c) melhora do conforto térmico no microclima do usuário (possibilidade de adaptação de sistemas Task/Ambient Conditioning Systems - TAC, que permitem ajustes individuais de condições térmicas em pequenas zonas ocupadas, por meio de seus usuários, sem o comprometimento das condições em zonas comuns ou vizinhas); e

(d) facilidade na reconfiguração de leiaute (devido à possibilidade de reposicionamento das placas de piso elevado contendo os difusores) (LEITE; TRIBESS, 2006; YUSOF et al., 2006; KOSONEN; TAN, 2004; LEITE, 2003;

BAUMAN; ARENS, 1996; BAUMAN, 2003; SHIRAI; BAUMAN; ZAGREUS, 2003).

O objetivo desta pesquisa foi verificar, experimentalmente, como um sistema UFAD pode contribuir para a remoção de particulados e $\mathrm{CO}_{2}$ do ar de um ambiente sob seis diferentes condições de operação. Para essa verificação, tomaram-se como referência os parâmetros aceitáveis constantes na norma NBR 16401 (ABNT, 2008), na resolução Anvisa RE 09 (AGÊNCIA..., 2003) e na norma internacional ASHRAE 62.1 (AMERICAN..., 2004a).

O sistema em questão é responsável pela climatização de uma sala de aula de ensino de CAD para 48 alunos, situada no Departamento de Engenharia de Construção Civil da Escola Politécnica da USP. Os resultados obtidos forneceram maiores subsídios para que se compreendam melhor as características típicas desse tipo de sistema e, portanto, a atenção requerida às etapas de projeto, operação e manutenção do mesmo, visando-se a seu melhor desempenho.

\section{Material e métodos}

A sala onde a pesquisa foi desenvolvida possui geometria retangular, $180 \mathrm{~m}^{2}$ de área, e piso elevado com um plenum inferior de $28 \mathrm{~cm}$ de altura. Como principais fontes de calor, 25 estações de trabalho para 49 pessoas que desenvolvem atividades leves. Além disso, existe uma contribuição devido à radiação solar, por meio de $31 \mathrm{~m}^{2}$ de janelas de vidro ao fundo da sala (Figura 1).

Pessoas, mobiliário, materiais de acabamento e partículas em suspensão no ar eram as principais fontes de material particulado. 
Figura 1 - Sala de aula objeto de estudo

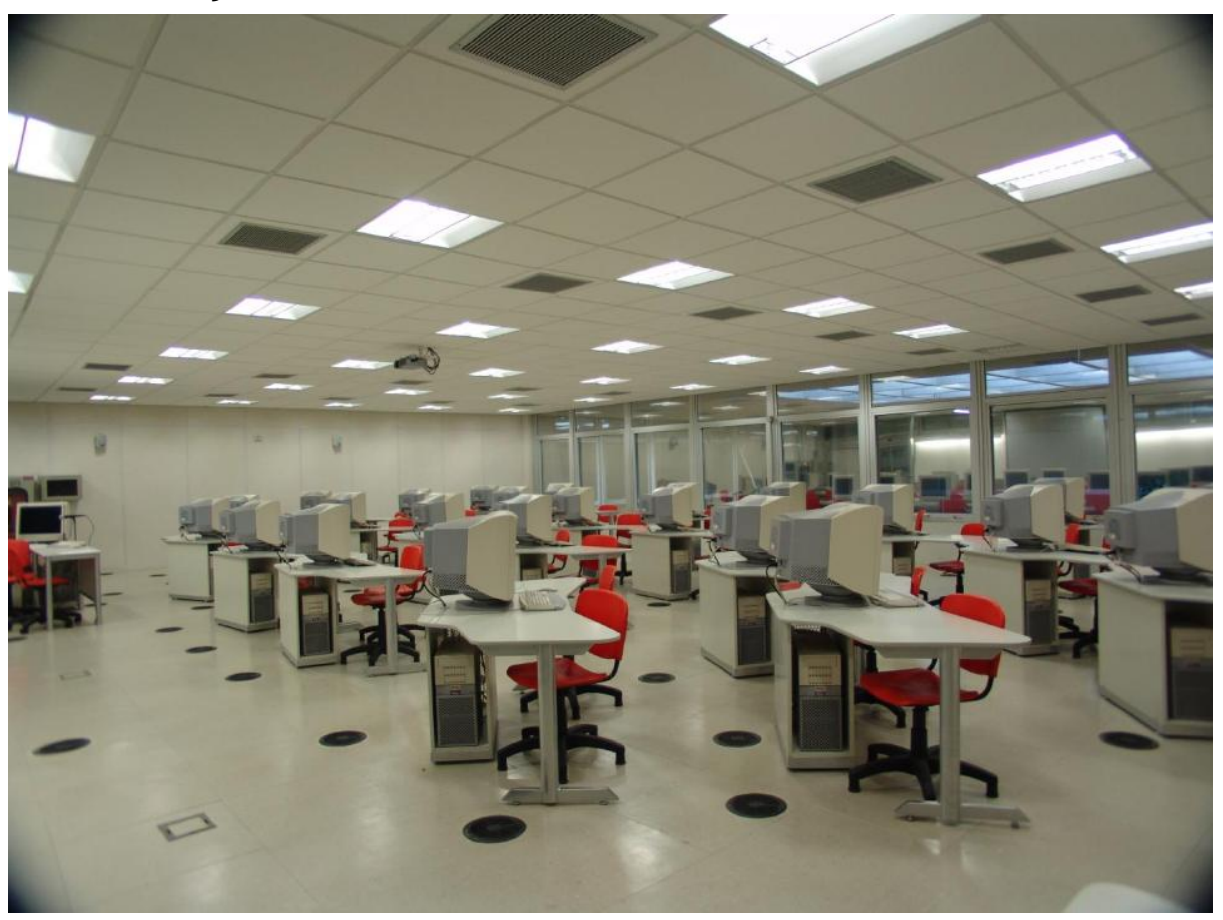

O sistema avaliado, de expansão indireta, é do tipo Vazão de Ar Variável (VAV), a partir da variação de frequência do ventilador do fan coil pelo sistema supervisório, fornecendo maior ou menor vazão de ar ao ambiente em função da carga térmica gerada. Possui capacidade de refrigeração de 7,5 TR e $5.500 \mathrm{~m}^{3} / \mathrm{h}$ de capacidade de vazão de ar. O plenum é pressurizado. É importante ressaltar que desde a instalação do sistema, em 2005, são realizadas manutenções preventivas mensais, por empresa qualificada, quando todos os filtros, que são do tipo F5, são trocados. O ar filtrado e condicionado é insuflado no ambiente por meio de 77 difusores com jato de ar do tipo espiralado ( $\varnothing$ $200 \mathrm{~mm}$ ), e a exaustão do ar é forçada por um ventilador, por meio de 16 grelhas distribuídas homogeneamente no teto. Sabe-se que a temperatura do ar de insuflamento nesse tipo de sistema é mais alta que a do sistema com insuflamento pelo teto, o que é conseguido por meio de uma mistura de ar resfriado no fan coil com um percentual de ar quente do retorno, efetuada numa caixa de mistura.

O sistema de automação e controle adotado foi definido com base em uma estratégia de controle específica para esse tipo de sistema de ar condicionado, visando atender às exigências de conforto térmico e renovação de ar para uma sala de aula, mantendo-se a eficiência energética. A estratégia de controle foi elaborada a partir de cinco rotinas: (a) a frequência de rotação do ventilador do fan coil varia para manter constante o diferencial de pressão entre o plenum e o ambiente $(\Delta \mathrm{P})$;

(b) a frequência de rotação do ventilador do retorno varia para manter constante o diferencial de temperatura $(\Delta \mathrm{T})$ entre o ar de retorno e o ar de insuflamento (mistura);

(c) a válvula de água gelada da serpentina do fan coil modula, para que a temperatura do ar frio seja mantida em torno de determinado valor;

(d) o damper de bypass de retorno e o damper de retorno para ofan coil modulam inversamente, para que se atinja o valor preestabelecido da temperatura de insuflamento; e

(e) os dampers de expurgo e de ar externo modulam diretamente e de acordo com os valores de entalpia do ar de retorno e do ar externo.

Primeiramente, foi essencial à pesquisa levar em conta o tipo de ambiente (sala de aula) e o tipo de atividade desenvolvida (leve). Neste caso, devido à semelhança com atividades de escritório, foi considerada taxa metabólica $\mathrm{M}=1,2$ met ou 69,6 $\mathrm{W} / \mathrm{m}^{2}$. Em relação ao isolamento térmico dos trajes utilizados em uma sala de aula localizada em São Paulo, o intervalo adotado foi $0,5 \leq \mathrm{I} \leq 1,0$ clo. $\mathrm{O}$ método utilizado seguiu procedimentos baseados nas normas ISO 7726 (INTERNATIONAL..., 1998), ASHRAE 55 (AMERICAN..., 2004b) e NBR 16401 (ABNT, 2008), bem como nos procedimentos adotados por Leite (2003) e Ikeda 
(2008), considerando-se condições de conforto térmico para a temperatura operativa de $21^{\circ} \mathrm{C} \leq \mathrm{T}$ $\leq 26{ }^{\circ} \mathrm{C}$ (ao nível $0,60 \mathrm{~m}$, variando-se $1{ }^{\circ} \mathrm{C}$ na temperatura do ar por condição de operação do sistema), $0,10<\mathrm{v}<0,30 \mathrm{~m} / \mathrm{s}$ para velocidade do ar, e $50 \%$ para a umidade relativa do ar.

As medições foram realizadas em dois diferentes períodos do ano sendo, o primeiro entre inverno e primavera, e o segundo entre primavera e verão, em seis dias alternados, variando-se o valor de temperatura do ar ambiente de acordo com o apresentado acima. Os intervalos horários aproximados foram: para sala ocupada, das $13 \mathrm{~h} 00$ às $17 \mathrm{~h} 00$, e para sala desocupada, das $17 \mathrm{~h} 00$ às $18 \mathrm{~h} 00$.

Na primeira parte do estudo, as concentrações de partículas foram avaliadas por seu total, e na segunda parte, por cinco diferentes tamanhos de partículas $(0,5,1,0,3,0,5,0$ e 10,0 $\mu \mathrm{m})$, devido às diferentes características entre os contadores de partículas utilizados. $\mathrm{Na}$ segunda parte, as concentrações de $\mathrm{CO}_{2}$ também foram medidas. Os poluentes do ar interior foram medidos em oito pontos do ambiente (pontos A-H da Figura 2), e nos níveis 1,10 m (zona de respiração para pessoas sentadas) e 2,60 m (exaustão do ar) simultaneamente, para sala ocupada e desocupada (Figura 3 e Figura 4). As concentrações de $\mathrm{CO}_{2}$ a $1,10 \mathrm{~m}$ foram medidas nesses mesmos oito pontos, e as concentrações próximas ao retorno do ar $(2,35$ m) foram medidas em dois pontos do ambiente (paredes laterais opostas), por meio de sensores fixados nas paredes.

Os dados referentes à temperatura do ar interior, à umidade relativa do ar e à velocidade do ar foram coletados por dois diferentes sistemas de aquisição: fixo na parede e portátil. $\mathrm{O}$ sistema fixo contém três sensores de temperatura do ar e um de umidade relativa do ar (marca Carrier), distribuídos pelas paredes laterais e posterior do ambiente, ao nível de 2,25 m. Eles pertencem ao sistema de controle e automação do sistema de ar condicionado, sendo acessados por uma interface dedicada no computador local. O sistema de controle do ar condicionado foi utilizado em perfeito estado de funcionamento, sendo realizadas manutenções mensais preventivas em todo o conjunto.

Figura 2 - Mapa dos pontos de medição

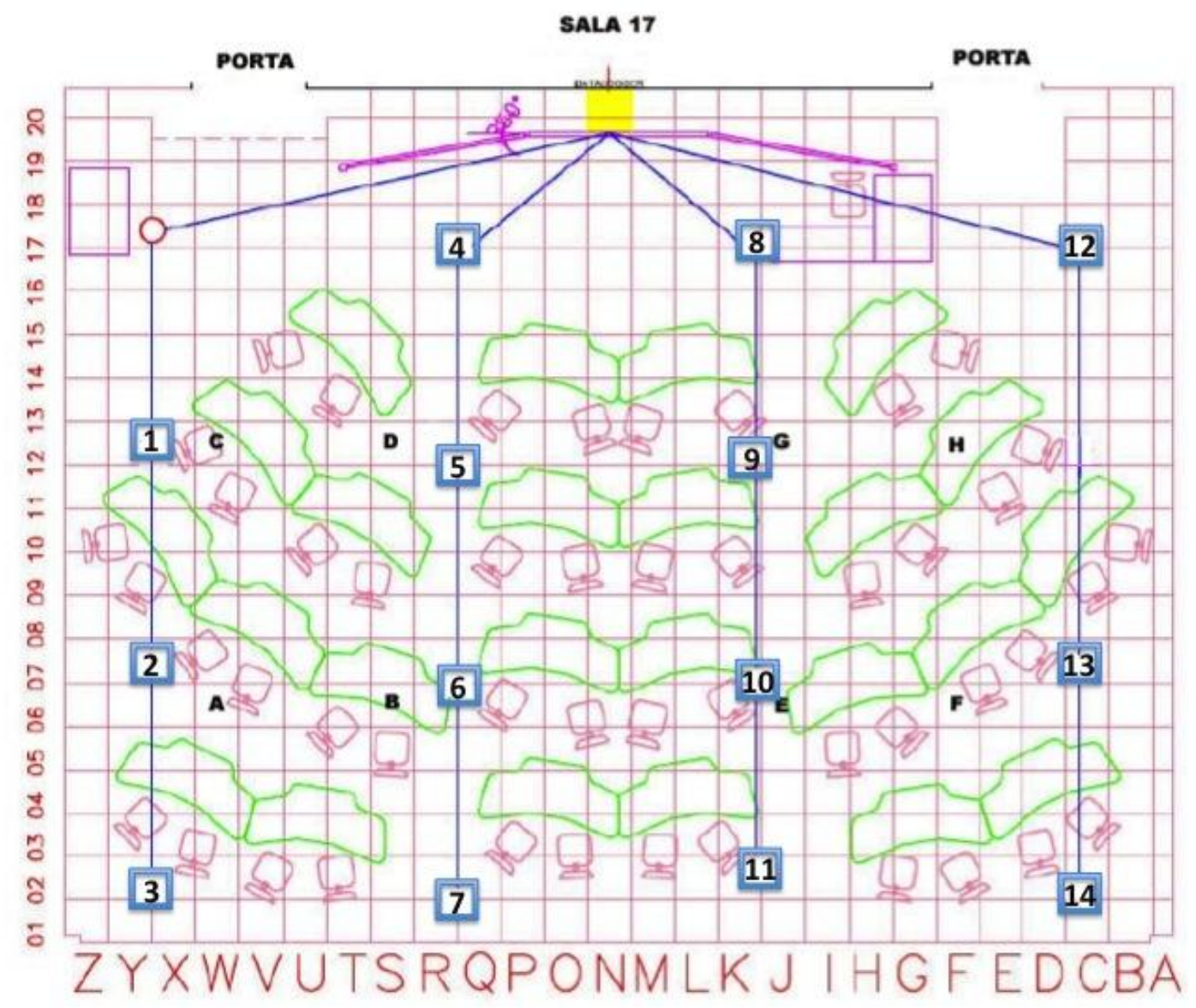

90 Marè, R.; Leite, B. C. C. 
Figura 3 - Suporte dos contadores de partículas

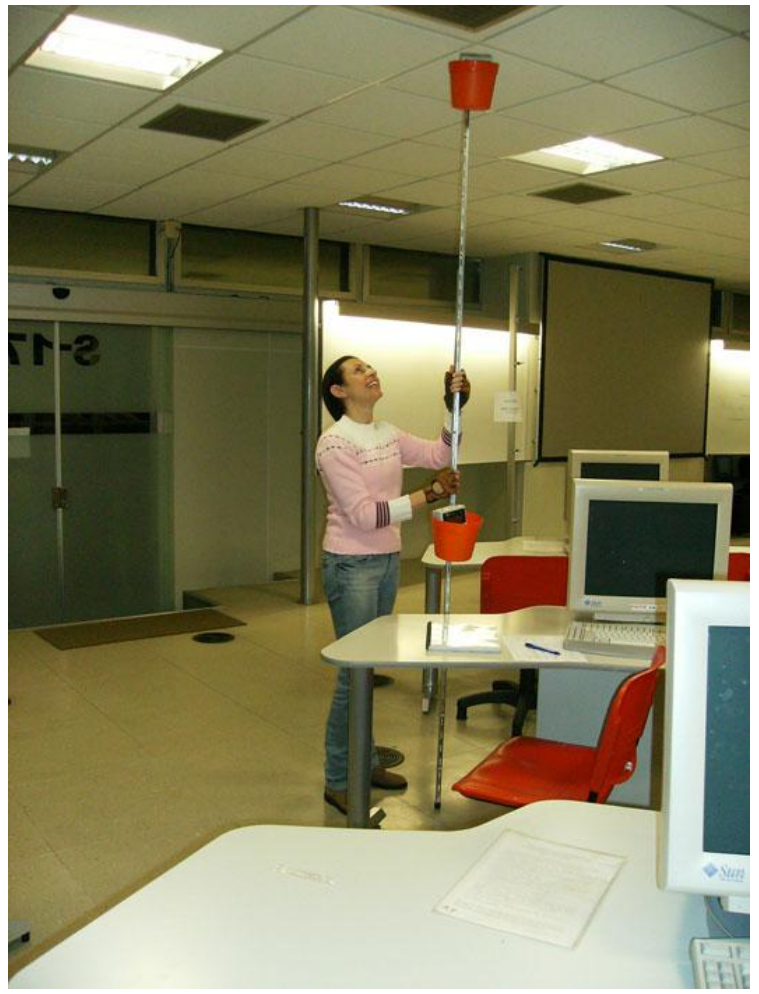

Figura 4 - Medições do total de partículas em suspensão e das concentrações de $\mathrm{CO}_{2}$ durante a aula

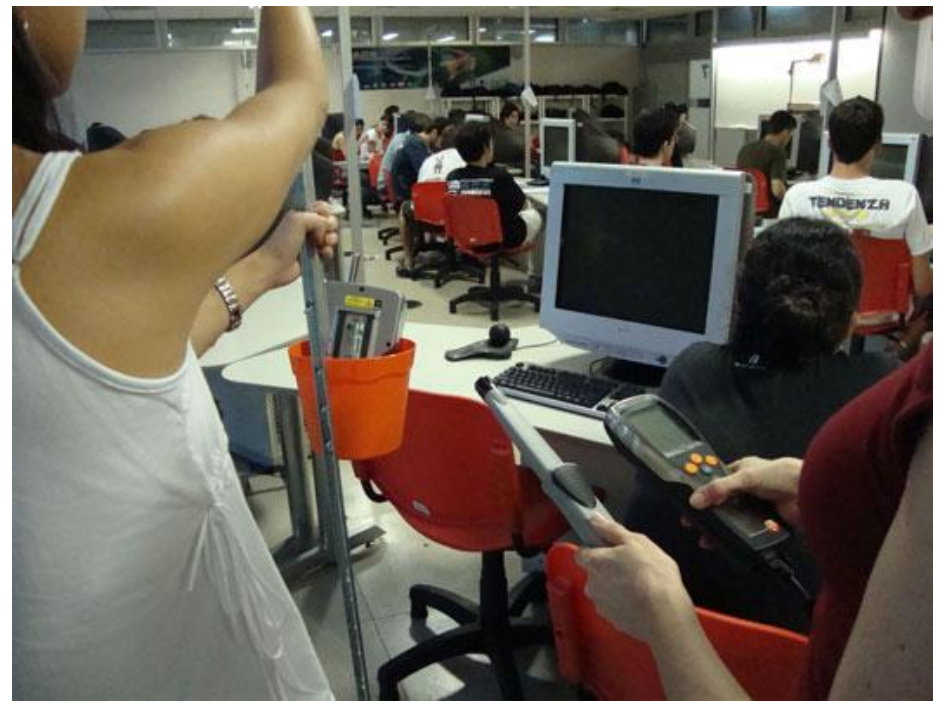

Na segunda parte do estudo, foram utilizados dois sensores de $\mathrm{CO}_{2}$ devidamente calibrados (marca E+E Elektronik), fixados na parede no mesmo nível, próximos aos sensores previamente descritos, nas paredes laterais, visando-se obter dados nas imediações do ponto de retorno do ar. Esses dados são armazenados em um servidor web remoto e são acessados por meio de um website dedicado, pertencente a um Sistema de Monitoramento Remoto da Qualidade do
Ambiente Interior (desenvolvido por meio de processo Pipe Fapesp n 07/59162-9).

Apresentam-se as características técnicas destes equipamentos na Tabela 1.

Com relação aos equipamentos portáteis, 84 pares de sensores de temperatura do ar e velocidade do ar foram fixados em seis diferentes níveis e quatorze pontos do ambiente (pontos 1-14 da Figura 2). Suas características técnicas são apresentadas na Tabela 2. 
Tabela 1 - Características técnicas dos sensores fixos na parede

\begin{tabular}{c|c|c|c|c}
\hline Sensor & Tipo & $\begin{array}{c}\text { Intervalo de } \\
\text { medição }\end{array}$ & $\begin{array}{c}\text { Incerteza de } \\
\text { medição }\end{array}$ & Quantidade \\
\hline $\begin{array}{c}\text { Temperatura do ar } \\
\text { interior } \\
\begin{array}{c}\text { Umidade relativa } \\
\text { do ar }\end{array}\end{array}$ & $\begin{array}{c}\text { Termorresistor, } \\
\text { com barreira } \\
\text { radiante }\end{array}$ & 0 a $90{ }^{\circ} \mathrm{C}$ & $0,1^{\circ} \mathrm{C}$ & 3 \\
$\mathrm{CO}_{2}$ & $\begin{array}{c}\text { Capacitivo } \\
\text { Infravermelho não } \\
\text { dispersivo }\end{array}$ & 0 a $2000 \mathrm{ppm}$ & $\begin{array}{c} \pm 50 \mathrm{ppm}+2 \% \\
\text { do valor medido }\end{array}$ & 2 \\
\hline
\end{tabular}

Tabela 2 - Características técnicas dos sensores portáteis

\begin{tabular}{c|c|c|c|c}
\hline Sensor & Tipo & $\begin{array}{c}\text { Intervalo de } \\
\text { medição }\end{array}$ & $\begin{array}{c}\text { Incerteza de } \\
\text { medição }\end{array}$ & Quantidade \\
\hline $\begin{array}{c}\text { Temperatura do ar } \\
\text { interior } \\
\begin{array}{c}\text { Velocidade do ar } \\
\text { interior }\end{array}\end{array}$ & $\begin{array}{c}\text { Termorresistor } \\
\text { omnidirecional }\end{array}$ & 0 a $90{ }^{\circ} \mathrm{C}$ & $0,1^{\circ} \mathrm{C}$ & 84 \\
\hline
\end{tabular}

Os dados são acessados por um programa de aquisição dedicado (software Aquis) e planilhas geradas pelo Microsoft Excel, que foram usadas para análises posteriores. Os sensores foram calibrados, e o software atualizado pelo fornecedor da solução à época do início das medições.

As concentrações de partículas em suspensão foram medidas por contadores de partículas portáteis, estando todos com certificados de calibração válidos à época de sua utilização.

$\mathrm{Na}$ primeira parte da pesquisa, foram utilizados equipamentos da marca Met One Instruments, modelo AEROCET 531. Possuem como princípio de operação a contagem individual de determinados tamanhos de partículas (diâmetro em micrometro) e a contagem total, valendo-se da dispersão da luz de laser, calculando a concentração em massa equivalente $\left(\mathrm{em} \mathrm{mg} / \mathrm{m}^{3}\right.$ ) por meio de algoritmo próprio.

Como características técnicas desses equipamentos, podem ser citados: intervalos de concentração de massa, PM1; PM2,5; PM7; PM10 e TPS (total de partículas em suspensão); intervalo de concentrações, $0-1 \mathrm{mg} / \mathrm{m}^{3}$; intervalo de amostragem, 2 min; incerteza de medição, $\pm 10 \%$.

$\mathrm{Na}$ segunda parte da pesquisa, foram utilizados dois contadores de partículas da marca Met One, modelo HHPC-6. Possuem como princípio de operação a contagem individual de determinados tamanhos de partículas (diâmetro em micrometro), valendo-se da dispersão da luz de laser, e apresentam o total de partículas por tamanho.

Como características técnicas desses equipamentos, podem ser citados: diâmetros de partículas 0,$5 ; 1,0 ; 3,0 ; 5,0$ e $10,0 \mu \mathrm{m}$; intervalo de amostragem, $3 \times 21 \mathrm{~s}$, com intervalo de $10 \mathrm{~s}$; eficiência na contagem, $50 \%$ a $0,3 \mu \mathrm{m}$ e $100 \%$ para partículas $>0,45 \mu \mathrm{m}$, recomendados pela JIS B9921 (JAPANESE...,1997).

Para medir os níveis de $\mathrm{CO}_{2}$ em diferentes pontos do ambiente, foi usado um equipamento portátil da marca Testo, Modelo 435, com sonda dedicada, com as seguintes características técnicas: intervalo de medição, 0 a 10.000 ppm; intervalo de amostragem manual, cerca de $1 \mathrm{~min} 20 \mathrm{~s}$; incerteza de medição: \pm 50 ppm $\mathrm{CO}_{2} \pm 2 \%$ do valor medido para a faixa de $0 \mathrm{a}+5.000 \mathrm{ppm}$ de $\mathrm{CO}_{2}$ e \pm 100 ppm de $\mathrm{CO}_{2} \pm 3 \%$ do valor medido para a faixa de $+5.001 \mathrm{a}+10.000 \mathrm{ppm}$ de $\mathrm{CO}_{2}$. O equipamento teve sua primeira utilização nesta pesquisa, tendo sido fornecido com certificado de calibração de fábrica, dentro do prazo de validade.

Os dados coletados por todos os equipamentos portáteis foram transferidos diariamente para um computador pessoal, para análises posteriores.

A princípio, foram adotados valores de algumas condições de operação do sistema, visando-se atingir os valores de temperatura do ar interior (21 ${ }^{\circ} \mathrm{C}$ a $26{ }^{\circ} \mathrm{C}$ ), de acordo com Leite (2003) (Tabela 3 e Tabela 4). 
Tabela 3 - Valores preestabelecidos para as condições operacionais do sistema (1 $1^{\text {a }}$ parte do estudo)

\begin{tabular}{l|c|c|c|c|c|c}
\hline \multicolumn{1}{c}{ Variável/Temperatura do Ar $\left({ }^{\circ} \mathbf{C}\right)$} & $\mathbf{2 1}$ & $\mathbf{2 2}$ & $\mathbf{2 3}$ & $\mathbf{2 4}$ & $\mathbf{2 5}$ & $\mathbf{2 6}$ \\
\hline Diferencial de Pressão $(\mathrm{Pa})$ & 5,00 & 5,00 & 4,00 & 3,00 & 5,00 & 3,00 \\
Temperatura do Ar Frio $\left({ }^{\circ} \mathrm{C}\right)$ & 13,0 & 13,0 & 14,0 & 15,0 & 14,0 & 15,0 \\
Diferencial de Temperatura do $\mathrm{Ar}\left({ }^{\circ} \mathrm{C}\right)$ & 8,0 & 7,0 & 6,0 & 6,0 & 6,0 & 7,0 \\
\hline
\end{tabular}

Tabela 4 - Valores preestabelecidos para as condições operacionais do sistema ( $2^{\mathrm{a}}$ parte do estudo)

\begin{tabular}{l|c|c|c|c|c|c}
\hline \multicolumn{1}{c|}{ Variável/Temperatura do Ar $\left({ }^{\mathbf{0}} \mathbf{C}\right)$} & $\mathbf{2 1}$ & $\mathbf{2 2}$ & $\mathbf{2 3}$ & $\mathbf{2 4}$ & $\mathbf{2 5}$ & $\mathbf{2 6}$ \\
\hline Diferencial de Pressão $(\mathrm{Pa})$ & 8,00 & 5,00 & 7,00 & 5,00 & 4,00 & 5,00 \\
Temperatura do Ar Frio $\left({ }^{\circ} \mathrm{C}\right)$ & 11,0 & 13,0 & 14,0 & 13,0 & 15,0 & 14,0 \\
Diferencial de Temperatura do $\operatorname{Ar}\left({ }^{\circ} \mathrm{C}\right)$ & 3,0 & 8,0 & 7,0 & 7,0 & 7,0 & 4,0 \\
\hline
\end{tabular}

Nas tabelas acima, o diferencial de pressão referese à diferença de valores entre o plenum e o ambiente; a temperatura do ar frio refere-se ao ponto de descarga do ar; e o diferencial de temperatura refere-se à diferença de valores entre o insuflamento e o retorno.

Os valores medidos permitiram que se determinasse o índice de efetividade na remoção de poluentes, tanto para particulados como para $\mathrm{CO}_{2}$, pela relação entre a concentração de poluentes no ar de exaustão e a concentração de poluentes na zona de respiração.

Variáveis relativas ao conforto térmico, tais como temperatura do ar e velocidade do ar, foram medidas em 14 pontos do ambiente e em seis diferentes níveis: 0,$10 ; 0,60 ; 1,10 ; 1,70 ; 2,00$ e 2,35 m (Figura 2 e Figura 5). É importante ressaltar que, para conforto térmico, a temperatura de referência é a temperatura operativa. Entretanto, no caso desta pesquisa, considerou-se a temperatura do ar (bulbo seco) como referência, porque o ambiente é considerado "moderado" e a temperatura radiante média é praticamente igual à do ar. De acordo com Fanger (1972), o ambiente pode ser considerado "moderado" pelo fato de as condições térmicas criadas no ambiente terem sido próximas às do conforto e pelo fato de as temperaturas não terem sofrido variações significativas durante o período de cada teste.

Variáveis relacionadas às condições operacionais do sistema, tais como temperatura do ar, umidade relativa do ar, diferencial de pressão entre o plenum e o ambiente, foram coletadas por sensores dedicados ao sistema de controle e automação.

\section{Resultados e discussão}

Os resultados apresentados abaixo correspondem à primeira etapa do estudo (período entre inverno e primavera) e à segunda parte do estudo (período entre primavera e verão).

\section{Primeira parte do estudo}

Visando-se atingir os valores de temperatura do ar de $21{ }^{\circ} \mathrm{C}$ a $26{ }^{\circ} \mathrm{C}$ (ao nível $0,60 \mathrm{~m}$ ), algumas combinações de valores das demais variáveis inerentes ao controle foram estabelecidas para a operação do sistema, conforme apresentado acima (Tabela 3 e Tabela 4). Os valores dessas variáveis lidos durante o período de medições, durante a operação do sistema de ar condicionado, são apresentados na Tabela 5 e referem-se à média dos valores durante o período ocupado. Nesta tabela, o diferencial de temperatura refere-se à diferença de valores entre plenum e retorno.

Os perfis de temperatura do ar (Figura 6) e velocidade do ar resultantes (Figura 7) foram construídos com os valores das médias de temperatura do ar medidas nos quatorze pontos do ambiente. É importante ressaltar que os valores indicados abaixo do nível zero $(0,00 \mathrm{~m})$ do gráfico da Figura 6 correspondem à temperatura do ar no ponto de descarga do duto de insuflamento no plenum. Uma característica desse tipo de sistema é o aumento de temperatura do ar desde o ponto de descarga até atingir o difusor (neste caso, no nível zero), de 2 a $3{ }^{\circ} \mathrm{C}$ em média. Até atingir o nível de $+0,10 \mathrm{~m}$, nível considerado como referência para os pés das pessoas, o ar fornecido troca calor com o ambiente e a temperatura aumenta em mais $1{ }^{\circ} \mathrm{C}$ aproximadamente. Respeitando-se a distância mínima de projeto de $0,80 \mathrm{~m}$ da pessoa ao difusor, a temperatura do ar que efetivamente entra em contato com os pés das pessoas já está em valores compatíveis para conforto. Inclusive, à altura de $0,60 \mathrm{~m}$, considerada como referência para conforto em ambientes climatizados artificialmente (ABNT, 2008), o ambiente já se encontra dentro da faixa recomendada (de 21 a $26{ }^{\circ} \mathrm{C}$ ). Em todas as condições de ensaio, conforme mostra o gráfico da Figura 6, o exposto acima se confirma, e não se evidencia qualquer situação de desconforto térmico. 
Figura 5 - Suportes dos sensores de temperatura e velocidade do ar (medições durante a aula)

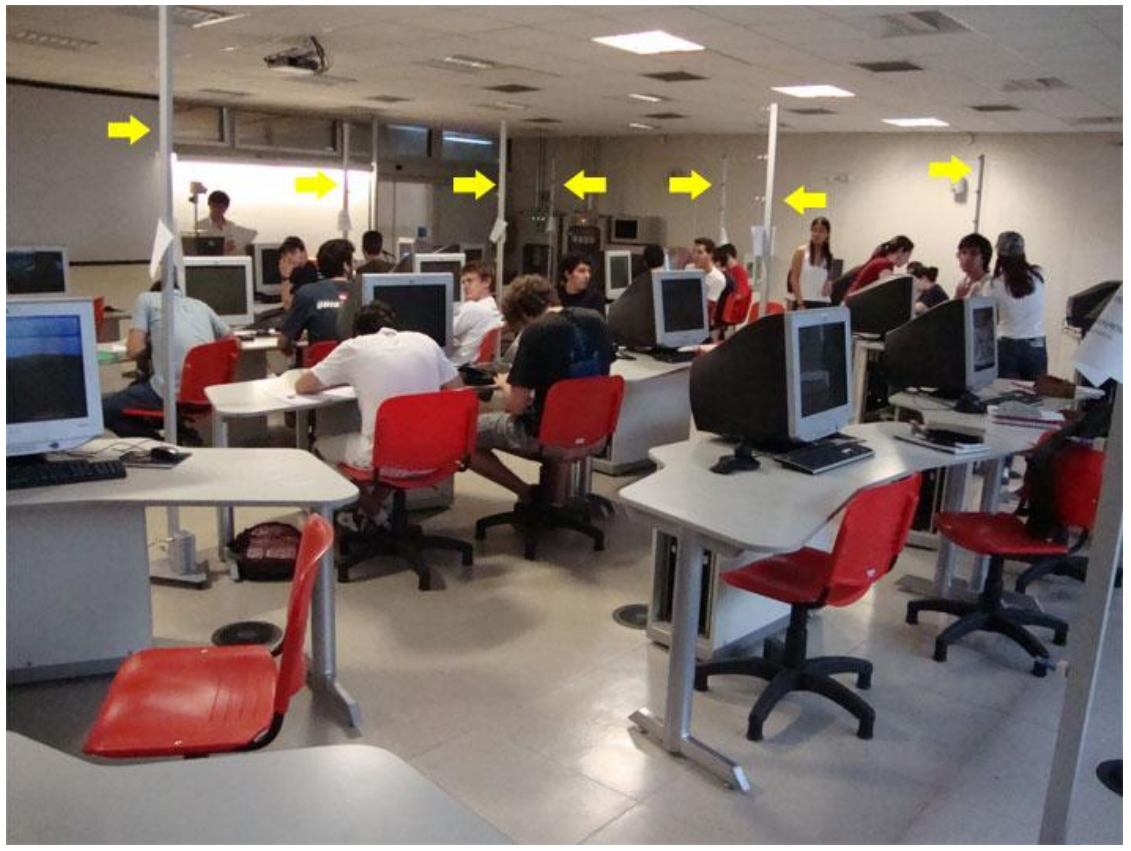

Tabela 5 - Condições operacionais resultantes - ambiente ocupado ( $1^{\mathrm{a}}$ parte do estudo)

\begin{tabular}{l|c|c|c|c|c|c}
\hline \multicolumn{1}{c|}{ Variável/Temperatura do ar $\left({ }^{\mathbf{0}} \mathbf{C}\right)$} & $\mathbf{2 1}$ & $\mathbf{2 2}$ & $\mathbf{2 3}$ & $\mathbf{2 4}$ & $\mathbf{2 5}$ & $\mathbf{2 6}$ \\
\hline Temperatura do Ar Externo $\left({ }^{\circ} \mathrm{C}\right)$ & 21,9 & 23,7 & 27,1 & 18,6 & 28,9 & 30,6 \\
Umidade Relativa do Ar Externo $(\%)$ & 62 & 58 & 46 & 74 & 47 & 47 \\
Diferencial de Pressão (Pa) & 4,50 & 5,07 & 4,01 & 3,01 & 5,87 & 3,69 \\
Temperatura do Ar no Plenum $\left({ }^{\circ} \mathrm{C}\right)$ & 17,9 & 19,4 & 19,4 & 19,6 & 22,5 & 22,3 \\
Temperatura do Ar no Retorno $\left({ }^{\circ} \mathrm{C}\right)$ & 23,2 & 24,4 & 23,6 & 23,2 & 27,7 & 27,4 \\
Diferencial de Temperatura $\left({ }^{\circ} \mathrm{C}\right)$ & 7,8 & 7,2 & 6,3 & 4,7 & 8,7 & 7,3 \\
Umidade Relativa do Ar Interior $(\%)$ & 55 & 55 & 56 & 63 & 53 & 57 \\
Umidade Relativa do Ar no Retorno $(\%)$ & 39 & 38 & 43 & 50 & 40 & 42 \\
Vazão de Insuflamento $\left(\mathrm{m}^{3} / \mathrm{h}\right)$ & $3.439,3$ & $3.574,0$ & $3.171,4$ & $2.200,6$ & $3.093,4$ & $1.282,9$ \\
Vazão do Ar de Retorno $\left(\mathrm{m}^{3} / \mathrm{h}\right)$ & $3.424,0$ & $4.242,4$ & $3.611,3$ & $3.401,8$ & $8.182,5$ & $4.572,6$ \\
\hline
\end{tabular}

Figura 6 - Perfis de temperatura do ar: ambiente ocupado ( $1^{\mathrm{a}}$ parte do estudo)

\section{Temperaturas Médias do Ar no Ambiente Sala Ocupada}

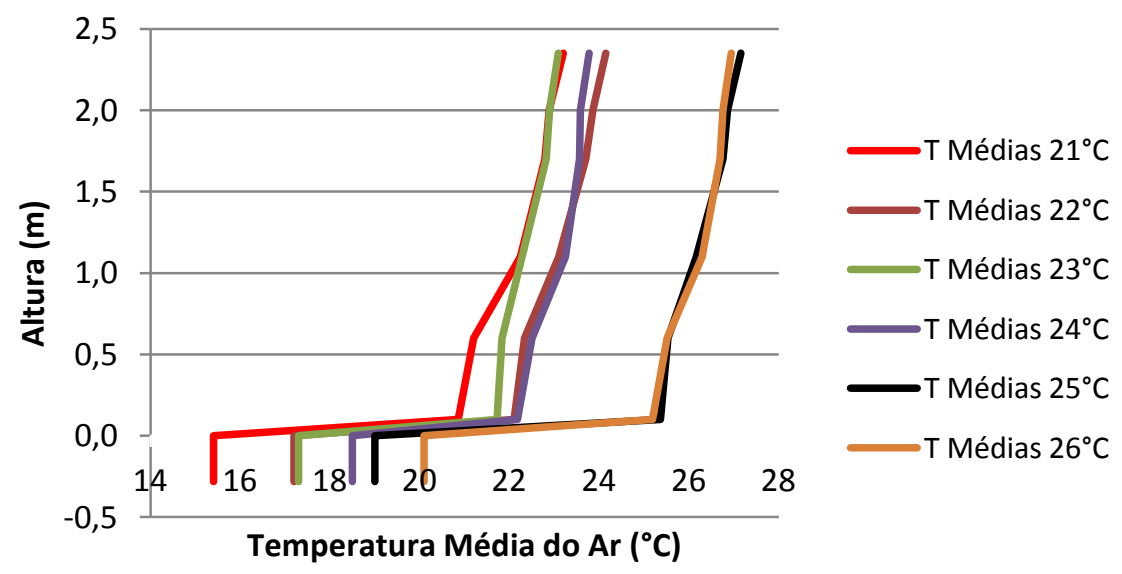

94 Marè, R.; Leite, B. C. C. 
Figura 7 - Perfis de velocidade do ar: ambiente ocupado ( ${ }^{\mathrm{a}}$ parte do estudo)

\section{Velocidades Médias do Ar no Ambiente Sala Ocupada}

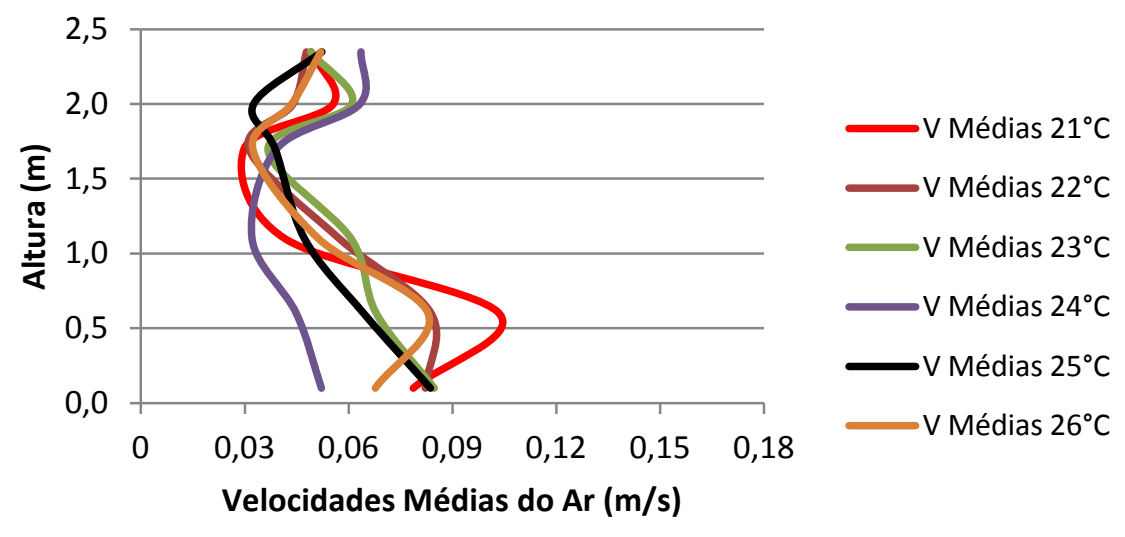

Pode-se observar que, entre os níveis $0,10 \mathrm{~m} \mathrm{e}$ $0,60 \mathrm{~m}$, a variação da temperatura do ar não foi significativa. A estratificação da temperatura (variação da temperatura do piso ao teto) é considerada um fenômeno típico do sistema com insuflamento de ar pelo piso (LEHRER; BAUMAN, 2003). Nesse caso, entre os níveis 0,10 $\mathrm{m}$ e $1,70 \mathrm{~m}$, a temperatura do ar apresentou um ganho ao redor de $2{ }^{\circ} \mathrm{C}$; no entanto, de acordo com os parâmetros da norma ISO 7730 (INTERNATIONAL..., 2005), com ganho menor que $3{ }^{\circ} \mathrm{C}$, mantêm-se as condições de conforto térmico.

Os perfis de velocidade do ar mostram que, na maioria dos pontos da zona ocupada, os valores estavam abaixo de $0,10 \mathrm{~m} / \mathrm{s}$. Em alguns casos, grandes movimentações de ar foram verificadas nos níveis $0,60 \mathrm{~m}$ e 2,00 $\mathrm{m}$, provavelmente devido ao ganho de carga térmica e aos efeitos do ventilador de exaustão respectivamente.

Observa-se na Figura 8 e na Figura 9 a relação entre o total de partículas em suspensão (TPS $\mathrm{mg} / \mathrm{m}^{3}$ ) a $1,10 \mathrm{~m}$ e $2,60 \mathrm{~m}$ e a temperatura do ar. TPS é a média dos valores dos oito pontos do ambiente onde essas variáveis foram medidas. Os valores de TPS para todas as condições de operação do sistema foram menores que $35 \mu \mathrm{g} / \mathrm{m}^{3}$. A resolução Anvisa RE 09 (2003) fornece como parâmetro máximo recomendável para contaminação química por aerodispersoides totais no ar em ambientes climatizados artificialmente de uso público e coletivo $80 \mu \mathrm{g} / \mathrm{m}^{3}$ como indicador do grau de pureza do ar e limpeza do ambiente climatizado. Na NBR 16401 (ABNT, 2008) assim como na ASHRAE 62.1 (AMERICAN..., 2004a), o parâmetro fornecido refere-se a material particulado (PM10), $50 \mu \mathrm{g} / \mathrm{m}^{3}$, também superior aos valores observados. Portanto, segundo esses referenciais, o ambiente analisado apresentou conformidade em relação ao total de partículas em suspensão em todos os dias de medições. Segundo a Organização Mundial de Saúde (WORLD..., 2006), os valores-limite aceitáveis para exposição dos usuários (média para 24 horas) são PM2,5: 25 $\mu \mathrm{g} / \mathrm{m}^{3}$ e PM10: $50 \mu \mathrm{g} / \mathrm{m}^{3}$. Uma análise mais apurada de valores de concentração em massa equivalente, por tamanho de partícula, poderia apontar uma não conformidade do ambiente para PM2,5. No entanto, essa análise não foi possível, devido às características técnicas dos contadores de partículas utilizados.

Comparando-se as duas figuras, valores maiores de TPS podem ser observados para ambiente ocupado, ficando evidente a influência da presença de pessoas. Com relação à influência da temperatura do ar sobre TPS, verificou-se que esses valores foram maiores para temperaturas do ar do ambiente mais altas (de $24{ }^{\circ} \mathrm{C}$ a $26^{\circ} \mathrm{C}$ ). Naqueles dias, os valores de temperatura do ar insuflado foram maiores (Tabela 5), apesar de o número de pessoas na sala ter sido praticamente o mesmo em todos os dias de medições. Esse fato pode indicar que existe uma relação entre TPS e a vazão de insuflamento, cujos valores foram menores para temperaturas do ar mais altas no ambiente.

Considerando que os testes experimentais foram realizados em ambiente na condição real de uso (uma sala de aula), a abertura das portas é uma ação imprevisível e incontrolável, favorecendo a infiltração de ar externo. Os valores de vazão de retorno do ar, indicados na Tabela 5, para os setpoints $25{ }^{\circ} \mathrm{C}$ e $26{ }^{\circ} \mathrm{C}$, apresentaram-se significativamente maiores que os valores de vazão 
de insuflamento, indicando claramente que houve infiltração de ar no ambiente. Esse fato pode ser uma das razões para valores mais altos de TPS, especialmente a $25^{\circ} \mathrm{C}$, com a entrada adicional de partículas no ambiente sem passar pelos filtros do sistema de climatização.

A variação de TPS (a $1,10 \mathrm{~m}$ e a $2,60 \mathrm{~m}$ ) com a velocidade do ar é representada na Figura 10, para ambiente ocupado, e na Figura 11, para ambiente desocupado. Aparentemente, não há relação entre essas variáveis, analisando-se o mesmo intervalo de variação de velocidade do ar. Outras situações precisam ser estudadas, pois, neste caso, os valores de velocidade do ar observados foram muito baixos (abaixo de $0,10 \mathrm{~m} / \mathrm{s}$ ).

Os índices IERP foram obtidos pela relação $\mathrm{TPS}_{2,60} / \mathrm{TPS}_{1,10}$, onde TPS é a média dos valores medidos nos oito pontos do ambiente, nos níveis correspondentes $(2,60 \mathrm{~m} \mathrm{e} 1,10 \mathrm{~m})$. Como pode ser observado na Figura 12, na maior parte dos casos, os índices IERP foram maiores para ambiente ocupado, o que pode apontar uma relação com a presença de pessoas. Provavelmente isso ocorre devido à convecção natural, que facilita o transporte das partículas em suspensão aos níveis mais altos, gerando maiores concentrações no nível de exaustão do ar, comparando-se aos valores observados na zona de respiração. Os índices IERP apresentaram-se em torno do valor 1, o que pode ser considerado adequado para o tipo de sistema avaliado. Podem-se considerar como causas das variações a incerteza de medição dos equipamentos ( $\pm 10 \%$ do valor medido), o fato de os valores de TPS medidos serem muito baixos (próximos ao fundo de escala dos equipamentos) e a influência de variáveis fora de controle, como, por exemplo, infiltração (ambiente em condições reais de uso).

Figura 8 - TPS X Temperatura do ar: ambiente ocupado
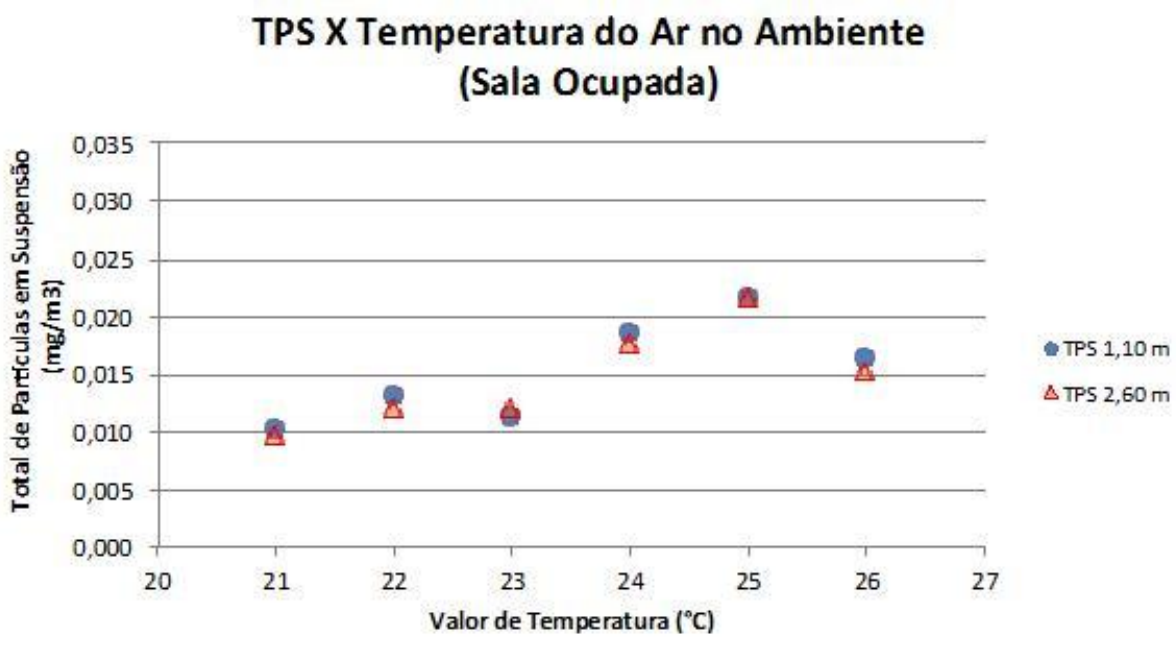

Figura 9 - TPS X Temperatura do ar: ambiente desocupado

TPS X Temperatura do Ar no Ambiente

(Sala Desocupada)

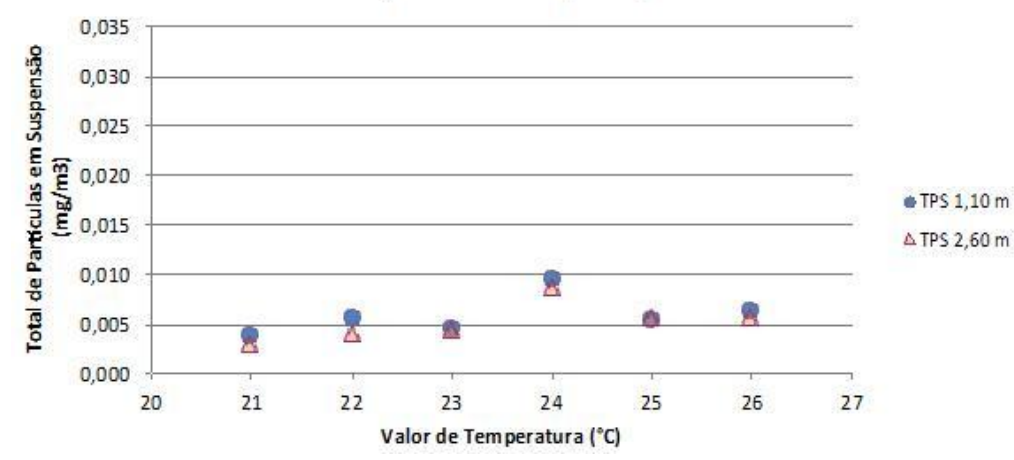

96 Marè, R.; Leite, B. C. C. 
Figura 10 - TPS X Velocidade do ar: ambiente ocupado

TPS X Velocidade do Ar no Ambiente

(Sala Ocupada)

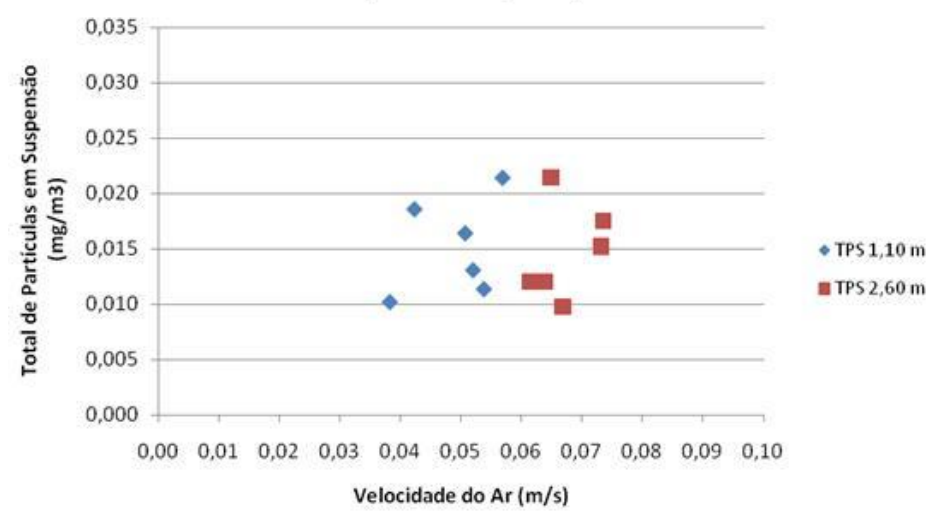

Figura 11 - TPS X Velocidade do ar: ambiente desocupado

TPS X Velocidade do Ar no Ambiente

(Sala Desocupada)

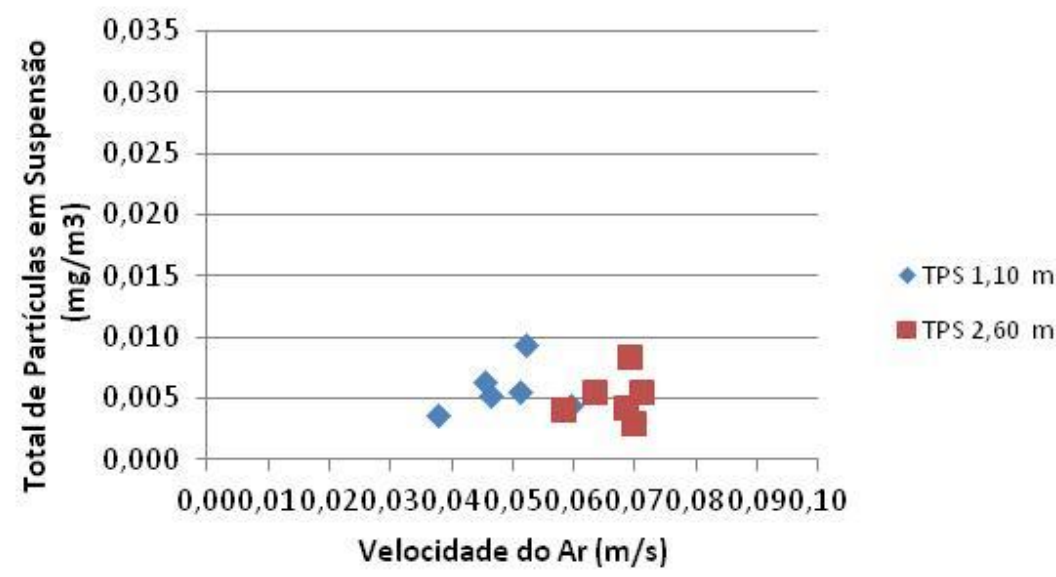

Figura 12 - IERP X Valores de temperatura do ar (ambiente ocupado e desocupado)

IERP X Setpoint de Temperatura

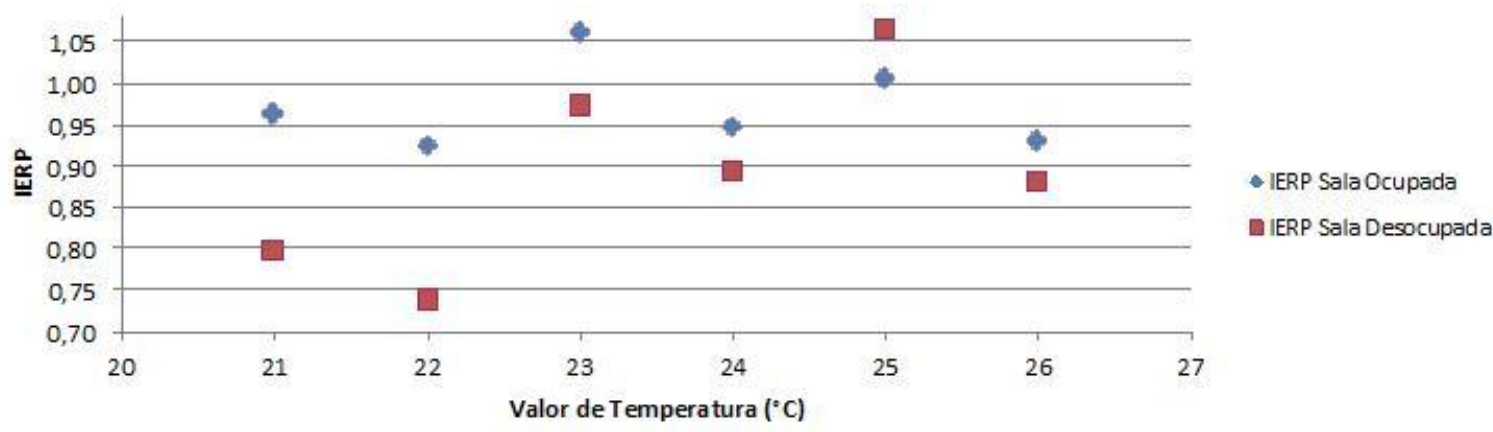




\section{Segunda parte do estudo}

Foram repetidos nesta etapa os procedimentos adotados na primeira parte do estudo, visando-se atingir os valores de temperatura do ar de $21{ }^{\circ} \mathrm{C}$ a $26{ }^{\circ} \mathrm{C}$ (ao nível 0,60 m). Algumas combinações de valores das demais variáveis foram estabelecidas para o sistema (Tabela 4), e as condições de operação resultantes são apresentas na Tabela 6 , onde $\mathrm{o}$ diferencial de temperatura refere-se à diferença de valores entre plenum e retorno.

Os valores apresentados na Tabela 6 referem-se aos valores médios durante o período de ambiente ocupado. Pode ser observado que algum problema técnico ocorreu com os sensores a $24{ }^{\circ} \mathrm{C}$ (exceto para temperatura do ar externo e umidade relativa do ar), quando os valores não foram registrados. $\mathrm{O}$ mesmo pode ser constatado em relação ao sensor de vazão do ar de retorno, o que inviabilizou a avaliação desse parâmetro nesta etapa.

Apresentam-se, a seguir, os perfis obtidos de temperatura do ar (Figura 13) e velocidade do ar (Figura 14), a partir das medições realizadas. Os valores referem-se às médias obtidas a partir dos valores medidos de temperatura do ar e velocidade do ar, nos quatorze pontos do ambiente. Os valores ao nível -0,5 m correspondem à temperatura do ar insuflado para cada valor de temperatura do ar.

No que concerne à variação da temperatura do ar, foi observado o mesmo comportamento da primeira etapa do estudo. A estratificação da temperatura avaliada entre os níveis $0,10 \mathrm{~m}$ e 1,70 $\mathrm{m}$ apresentou um ganho de cerca de $2^{\circ} \mathrm{C}$, portanto, dentro dos parâmetros da norma ISO 7730 (DEUTSCHES..., 2005).

Os perfis de velocidade do ar mostram que, na maior parte dos pontos da zona ocupada, os valores foram inferiores a $0,10 \mathrm{~m} / \mathrm{s}$. Em alguns casos, grandes movimentações de ar foram observadas nos níveis $0,60 \mathrm{~m}$ e 2,00 m, devido às características do sistema avaliado (distribuição de ar pelo piso): ganho de carga térmica e efeitos do ventilador de exaustão do ar respectivamente.

Os valores de TPS foram medidos para cada tamanho de partícula suportado pelos equipamentos em questão $(0,5 ; 1,0 ; 3,0 ; 5,0$ e 10,0 $\mu \mathrm{m})$, distintos dos equipamentos da primeira etapa.

Com base nesses dados, os índices IERP foram calculados para cada tamanho de partícula, sendo os maiores valores observados para ambiente ocupado, o que corrobora as observações prévias sobre a influência de pessoas. Na Figura 15 os resultados para os índices IERP para cinco diferentes tamanhos de partículas em suspensão podem ser analisados para cada setpoint de temperatura do ar. Os índices IERP para partículas com $0,5 \mu \mathrm{m}$ foram quase sempre próximos ou menores que 1,0. Para partículas com 1,0 $\mu \mathrm{m}$, eles foram sempre maiores que 1,0. Os melhores índices IERP foram observados para partículas de $10 \mu \mathrm{m}, 5 \mu \mathrm{m}$ e $3 \mu \mathrm{m}$, mostrando maior contribuição do sistema na remoção de partículas com tamanhos maiores ou iguais a 1,0 $\mu \mathrm{m}$. Todos os índices IERP foram maiores que 1,0 para os setpoints de $22{ }^{\circ} \mathrm{C}$ e $26^{\circ} \mathrm{C}$, o que indica que, provavelmente, naqueles dias as melhores condições de operação do sistema foram adotadas.

Tabela 6 - Condições Operacionais - ambiente ocupado ( $2^{\mathrm{a}}$ parte do estudo)

\begin{tabular}{l|c|c|c|c|c|c}
\hline \multicolumn{1}{c|}{ Variável / Temperatura do ar $\left(\mathbf{~}^{\mathbf{O}} \mathbf{C}\right)$} & $\mathbf{2 1}$ & $\mathbf{2 2}$ & $\mathbf{2 3}$ & $\mathbf{2 4}$ & $\mathbf{2 5}$ & $\mathbf{2 6}$ \\
\hline Temperatura do Ar Externo $\left({ }^{\circ} \mathrm{C}\right)$ & 32,3 & 28,2 & 35,4 & 33,7 & 30,4 & 35,8 \\
Umidade Relativa do Ar Externo $(\%)$ & 41 & 62 & 40 & 43 & 48 & 31 \\
Diferencial de Pressão $(\mathrm{Pa})$ & 6,15 & 4,49 & 7,03 & ---- & 4,04 & 4,99 \\
Temperatura do Ar no Plenum $\left({ }^{\circ} \mathrm{C}\right)$ & 17,5 & 20,0 & 20,1 & ---- & 21,9 & 21,9 \\
Temperatura do Ar no Retorno $\left({ }^{\circ} \mathrm{C}\right)$ & 24,2 & 25,3 & 27,3 & ---- & 27,9 & 28,8 \\
Diferencial de Temperatura $\left({ }^{\circ} \mathrm{C}\right)$ & 8,5 & 10,5 & 9,5 & ---- & 9,3 & 10,5 \\
Umidade Relativa do Ar Interior $(\%)$ & 57 & 54 & 57 & ---- & 56 & 51 \\
Umidade Relativa do Ar Insuflado $(\%)$ & 68 & 78 & 74 & ---- & 76 & 68 \\
Umidade Relativa do Ar no Retorno $(\%)$ & 38 & 39 & 39 & ---- & 44 & 33 \\
Vazão de Insuflamento $\left(\mathrm{m}^{3} / \mathrm{h}\right)$ & $3.223,3$ & $4.031,4$ & $3.814,5$ & ---- & $2.864,2$ & $3.247,2$ \\
Vazão do Ar de Retorno $\left(\mathrm{m}^{3} / \mathrm{h}\right)$ & ---- & ---- & ---- & ---- & ---- & ---- \\
\hline
\end{tabular}

98 Marè, R.; Leite, B. C. C. 
Figura 13 - Perfis de temperatura do ar (ambiente ocupado)

Temperaturas Médias do Ar no Ambiente

Sala Ocupada

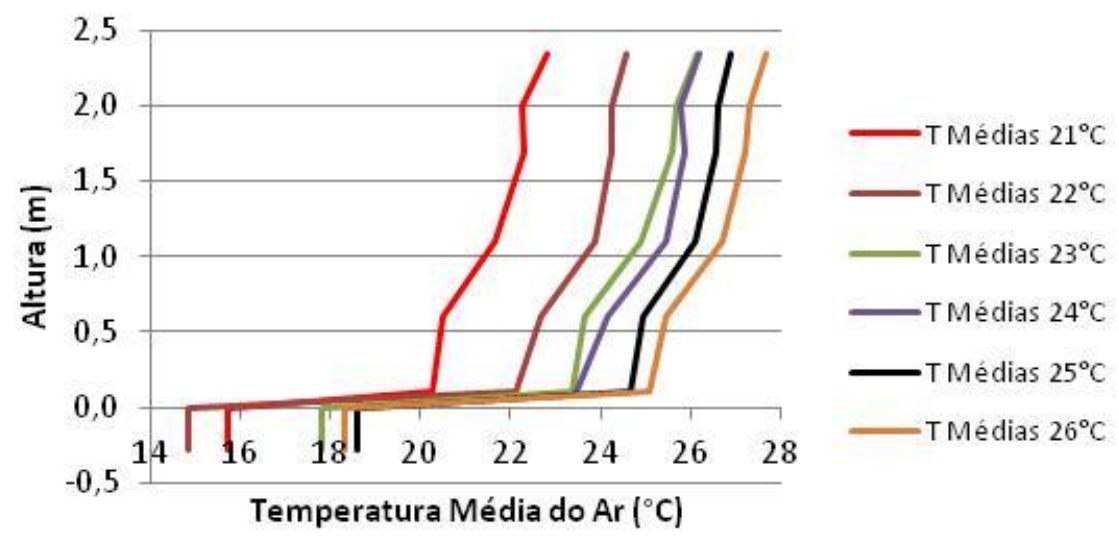

Figura 14 - Perfis de velocidade do ar (ambiente ocupado)

Velocidades Médias do Ar no Ambiente

Sala Ocupada

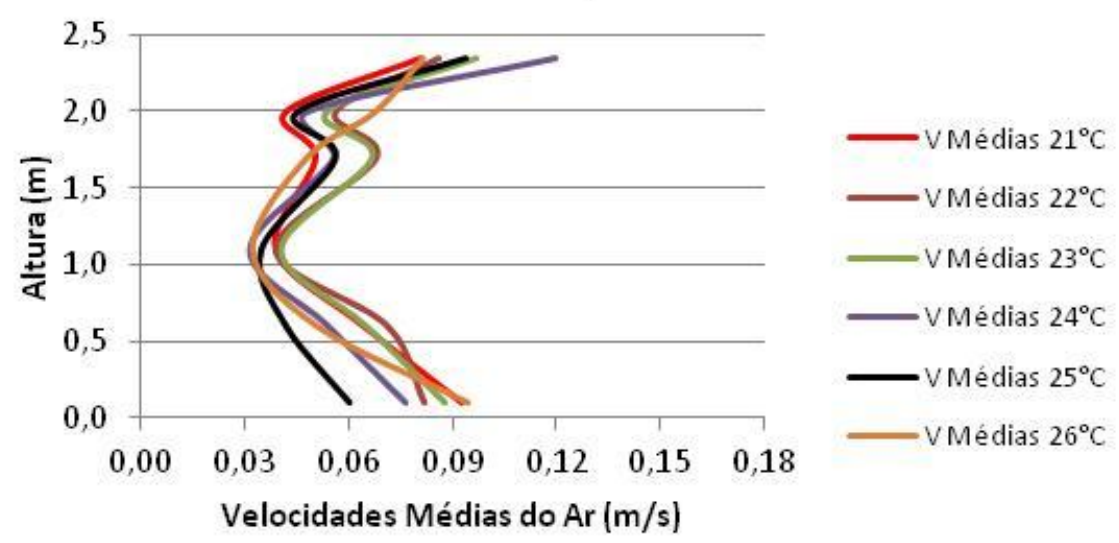

Figura 15 - IERP por tamanho de partícula X valor de temperatura do ar (ambiente ocupado)

\section{IERP X Setpoint de Temperatura}

(Sala Ocupada)

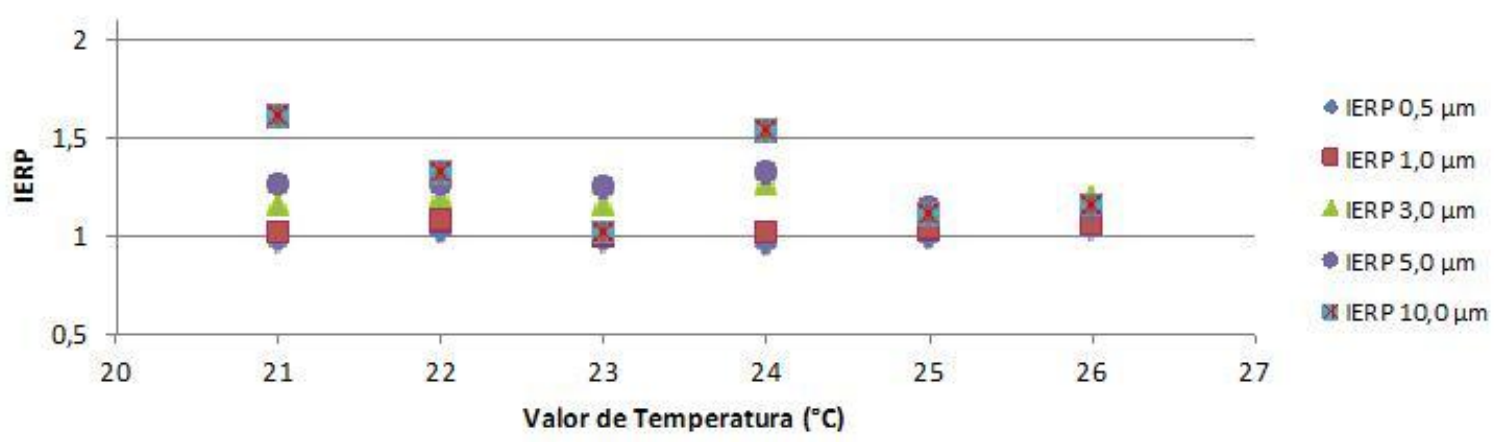


Os índices de efetividade na remoção de $\mathrm{CO}_{2}$, $\mathrm{IERCO}_{2}$, foram obtidos pela relação $\mathrm{CO}_{2-2,60} / \mathrm{CO}_{2}$ 1,10 , onde os números na Tabela 7 representam a média dos valores medidos para concentrações de $\mathrm{CO}_{2}$ nos oito pontos do ambiente, aos níveis correspondentes.

Em relação à concentração de $\mathrm{CO}_{2}$ no ar interior, o valor máximo recomendável pela RE 09 da Anvisa para contaminação química por dióxido de carbono é de 1.000 ppm. A NBR 16401 (ABNT, 2008) (com critérios baseados na ASHRAE 62.1) admite uma diferença de 700 ppm entre ar interno e externo, considerando concentração no recinto de 1.100 ppm a 1.300 ppm, e concentração de 400 ppm a $600 \mathrm{ppm}$, frequentemente verificada no ar exterior. Esse critério também é preconizado pela Occupational Safety and Health Administration (OSHA, 2013), em tópico dedicado à qualidade do ar interior em escolas, ou seja, os valores das concentrações de $\mathrm{CO}_{2}$ apresentados (Tabela 7) mostram a conformidade do ambiente objeto de estudo com esses referenciais em todos os dias de medições.
Os resultados dos índices $\mathrm{IERCO}_{2}$ para todas as condições de operação do sistema (Figura 16), tanto para ambiente ocupado como desocupado, ficaram ao redor de $1,0\left(0,98\right.$ para $25^{\circ} \mathrm{C}$, ambiente ocupado) ou superiores $\left(1,16\right.$ para $22^{\circ} \mathrm{C}$, ambiente desocupado). Portanto, esse sistema mostrou-se eficaz na remoção de $\mathrm{CO}_{2}$ do ambiente. No entanto, os valores mais altos foram observados em ambiente desocupado. Isso pode ser justificado pela influência das concentrações de $\mathrm{CO}_{2}$ no ar externo (não medidas neste estudo), ou pelo horário em que as medições foram realizadas. Para ambiente desocupado, as medições foram feitas apenas alguns minutos após os alunos deixarem a sala de aula. Provavelmente não houve tempo suficiente para a renovação do ar interior, mantendo as concentrações de $\mathrm{CO}_{2}$ perto da exaustão maiores que as concentrações na zona de respiração. Os maiores índices $\mathrm{IERCO}_{2}$, tanto para ambiente ocupado como desocupado, ocorreram a $22{ }^{\circ} \mathrm{C}$, o que indica que, nesse dia, as melhores condições de operação do sistema foram adotadas. A $22{ }^{\circ} \mathrm{C}$, foi observada uma maior estratificação da temperatura, o que pode ter influenciado também nos resultados de $\mathrm{IERCO}_{2}$.

Tabela 7 - Concentrações de $\mathrm{CO}_{2}$ e IERCO 2 (valores médios)

\begin{tabular}{|c|c|c|c|c|c|c|}
\hline \multirow{2}{*}{$\begin{array}{c}\text { Temperatura } \\
\text { do ar }\left({ }^{\circ} \mathrm{C}\right)\end{array}$} & \multicolumn{3}{|c|}{$\mathrm{CO}_{2}(\mathrm{ppm})$ Ambiente ocupado } & \multicolumn{3}{|c|}{$\mathrm{CO}_{2}(\mathrm{ppm})$ Ambiente desocupado } \\
\hline & $\mathrm{h}=1,10 \mathrm{~m}$ & $\mathrm{~h}=\mathbf{2 , 6 0 \mathrm { m }}$ & $\mathrm{IERCO}_{2}$ & $\mathrm{~h}=1,10 \mathrm{~m}$ & $\mathrm{~h}=2,60 \mathrm{~m}$ & $\mathrm{IERCO}_{2}$ \\
\hline 21 & 582 & 607 & 1,04 & 584 & 614 & 1,05 \\
\hline 22 & 627 & 672 & 1,07 & 468 & 542 & 1,16 \\
\hline 23 & 697 & 741 & 1,06 & 684 & 715 & 1,05 \\
\hline 24 & 666 & 685 & 1,03 & 496 & 546 & 1,10 \\
\hline 25 & 788 & 772 & 0,98 & 733 & 772 & 1,05 \\
\hline 26 & 662 & 674 & 1,02 & 643 & 684 & 1,06 \\
\hline
\end{tabular}

Figura 16 - IERCO 2 X Valor de temperatura do ar (ambiente ocupado e desocupado)

IERCO ${ }_{2} \mathrm{X}$ Valor de Temperatura

(Sala Ocupada e Desocupada)

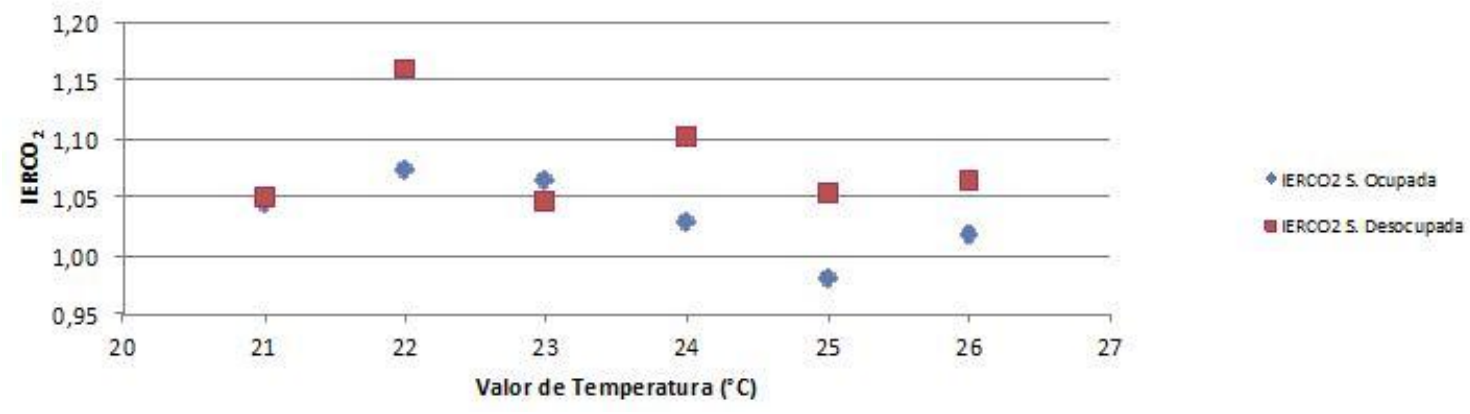

100 Marè, R.; Leite, B. C. C. 
Se também tivessem sido realizadas medições simultâneas de material particulado e $\mathrm{CO}_{2}$, nos níveis $1,10 \mathrm{~m}$ e $2,60 \mathrm{~m}$ no ar externo ao ambiente, os índices de efetividade na remoção de cada poluente poderiam ser mais bem avaliados pelas equações 1 e 2 :

$$
\begin{aligned}
& \mathrm{IERP}=\left(\mathrm{TPS}_{\mathrm{A} 2,60}-\mathrm{TPS}_{\mathrm{E} 2,60}\right) /\left(\mathrm{TPS}_{\mathrm{A} 1,10}-\mathrm{TPS}_{\mathrm{E} 1,10}\right) \\
& \text { Eq. } 1 \\
& \mathrm{IERCO}_{2}=\left(\mathrm{CO}_{2-\mathrm{A} 2,60}-\mathrm{CO}_{2-\mathrm{E} 2,60}\right) /\left(\mathrm{CO}_{2-\mathrm{A} 1,10}-\right. \\
& \left.\mathrm{CO}_{2-\mathrm{E} 1,10}\right) \text { Eq. } 2
\end{aligned}
$$

A: está associada às medições realizadas no ambiente; e

E: às medições realizadas no exterior, aos níveis correspondentes.

\section{Conclusão}

Esse sistema com insuflamento de ar pelo piso mostrou-se eficaz na remoção de material particulado e $\mathrm{CO}_{2}$ do ambiente, sob todas as condições de operação estipuladas, visto que os índices observados foram próximos ou superiores à unidade. Conforme exposto por diversos autores, essa característica é típica desse tipo de sistema.
Para o TPS, o melhor índice IERP foi $1,06\left(1^{\mathrm{a}}\right.$ parte do estudo a $23{ }^{\circ} \mathrm{C}$ ), e, para $\mathrm{CO}_{2}$, o melhor índice $\mathrm{IERCO}_{2}$ foi 1,07 ( $2^{\mathrm{a}}$ parte do estudo a 22 ${ }^{\circ} \mathrm{C}$ ), ambos para ambiente ocupado.

Com base nesses resultados, pode-se concluir que as melhores condições operacionais do sistema para cada etapa do estudo, ou seja, aquelas que proporcionaram os maiores índices de efetividade na remoção de poluentes (IERP e IERCO ${ }_{2}$ ), são as constantes das Tabelas 8 e 9 abaixo.

Os resultados obtidos nesta pesquisa constituem mais uma contribuição para que se entenda melhor o sistema com insuflamento de ar pelo piso, especialmente pelo fato de a pesquisa ter sido realizada sob condições reais de uso do ambiente, quando muitos fatores externos podem influir nos resultados. Além disso, na totalidade dos testes, os valores de particulados e de $\mathrm{CO}_{2}$ medidos foram muito pequenos, sempre no fundo de escala dos equipamentos e muito próximos dos valores das incertezas de medição dos equipamentos, o que dificulta conclusões mais consistentes, mas não invalida a pesquisa. Ao contrário, os resultados apontam para a conclusão de que o sistema com distribuição de ar pelo piso (UFAD) possui boa capacidade para remover particulados e $\mathrm{CO}_{2}$ dos ambientes, se operado adequadamente.

Tabela 8 - Melhores condições de operação do sistema e condições climáticas correspondentes $\left(1^{\mathrm{a}}\right.$ etapa - IERP $=1,06$ )

\begin{tabular}{l|c}
\hline \multicolumn{1}{c|}{ Variável/Temperatura do ar $\left({ }^{\mathbf{0}} \mathbf{C}\right)$} & $\mathbf{2 3}$ \\
\hline Diferencial de Pressão $(\mathrm{Pa})$ & 4,00 \\
Temperatura do Ar no plenum $\left({ }^{\circ} \mathrm{C}\right)$ & 19,4 \\
Diferencial de Temperatura & 6,0 \\
entre plenum e retorno $\left({ }^{\circ} \mathrm{C}\right)$ & \\
\hline Temperatura do Ar Externo $\left({ }^{\circ} \mathrm{C}\right)$ & 27,1 \\
Umidade Relativa do Ar Externo $(\%)$ & 46 \\
\hline
\end{tabular}

Tabela 9 - Melhores condições de operação do sistema e condições climáticas correspondentes $\left(2^{\mathrm{a}}\right.$ etapa $\left.-\mathrm{IERCO}_{2}=1,07\right)$

\begin{tabular}{l|c}
\hline Variável/Temperatura do ar $\left({ }^{\mathbf{0}} \mathbf{C}\right)$ & $\mathbf{2 2}$ \\
\hline Diferencial de Pressão $(\mathrm{Pa})$ & 5,00 \\
Temperatura do Ar no plenum $\left({ }^{\circ} \mathrm{C}\right)$ & 20,0 \\
Diferencial de Temperatura & 8,0 \\
entre plenum e retorno $\left({ }^{\circ} \mathrm{C}\right)$ & \\
\hline Temperatura do Ar Externo $\left({ }^{\circ} \mathrm{C}\right)$ & 28,2 \\
Umidade Relativa do Ar Externo $(\%)$ & 62 \\
\hline
\end{tabular}




\section{Referências}

ABE, V. C.; INATOMI, T. A. H.; LEITE, B. C. C. Air Quality in UFAD Systems: literature overview. In: HEALTHY BUILDINGS: CREATING A HEALTHY INDOOR ENVIRONMENT FOR PEOPLE, 2006, Lisboa. Anais... Lisboa: IDMEC/FEUP, 2006.

AGÊNCIA NACIONAL DE VIGILÂNCIA SANITÁRIA. Resolução RE N 9. 2003.

AMERICAN SOCIETY OF HEATING, REFRIGERATING AND AIR-CONDITIONING ENGINEERS, INC. ASHRAE Standard 55: thermal environmental conditions for human occupancy. Atlanta, 2004b.

AMERICAN SOCIETY OF HEATING, REFRIGERATING AND AIR-CONDITIONING ENGINEERS, INC. ANSI/ASHRAE Standard 62.1. Ventilation for Acceptable Air Quality. Atlanta, 2004a.

\section{ASSOCIAÇÃO BRASILEIRA DE NORMAS} TÉCNICAS. NBR 16401: instalações de arcondicionado: sistemas centrais e unitários: parte 3: qualidade do ar interior. Rio de Janeiro, 2008.

BAUMAN, F. S., ARENS, E. A. Task/Ambient Conditioning Systems: engineering and application guidelines. California: Center for Environmental Design Research, University of California. Berkeley, 1996. 70 p.

BAUMAN, F. S. Underfloor Air Distribution (UFAD) Design Guide. United States of America: American Society of Heating, Refrigerating and Air-Conditioning Engineers, Inc. 2003. 237 p.

CERMAK, R.; MELIKOV, A. K. Air Quality and Thermal Comfort in an Office with Underfloor, Mixing and Displacement Ventilation. The International Journal of Ventilation, v. 5, n. 3, p. 323-332, 2006.

DEUTSCHES INSTITUT FÜR NORMUNG. DIN EN ISO 7730: ergonomics of the thermal environment: analytical determination and interpretation of thermal comfort using calculation of the PMV and PPD indices and local thermal comfort criteria. Berlin, 2005.

FANGER, P. O. Thermal Comfort: analysis and applications in environmental engineering. New York: McGraw-Hill Book Company, 1972.

IKEDA, M. J. Determinação de Índices de Ajuste no Controle de Sistema de Condicionamento de Ar do Tipo "Teto Frio". 190 f. São Paulo, 2008. Dissertação (Mestrado em Engenharia Civil) - Escola Politécnica, Universidade de São Paulo, São Paulo, 2008.
INTERNATIONAL STANDARDS

ORGANIZATION. ISO 7726: thermal

environments: instruments and methods for measuring physical quantities. Geneva, 1998.

\section{INTERNATIONAL STANDARDS}

ORGANIZATION. ISO 7730: ergonomics of the thermal environment: analytical determination and interpretation of thermal comfort using

calculation of the PMV and PPD indices and local thermal comfort criteria. Brussels, 2005.

JAPANESE STANDARDS ASSOCIATION. JIS

B 9921: light scattering automatic particle counter. Tokyo, 1997.

KOSONEN, R.; TAN, F. The Effect of Perceived Indoor Air Quality on Productivity Loss. Energy and Buildings, v. 36, n. 10, p. 981-986, 2004.

LEHRER, D. R.; BAUMAN, F. S. Hype Vs. Reality: new research findings on underfloor air distribution systems. CBE Database, 2003. Disponível em: <http://www.cbe.berkeley.edu/research/pdf_files/L ehrer2003_UFAD.pdf>. Acesso em: 30 jul. 2013.

LEITE, B. C. C. Sistema de Ar-Condicionado Com Insuflamento Pelo Piso em Ambientes de Escritórios: avaliação do conforto térmico e condições de operação. 152 f. São Paulo, 2003. Tese (Doutorado em Engenharia Civil) - Escola Politécnica, Universidade de São Paulo, São Paulo, 2003.

LEITE, B. C. C.; TRIBESS, A. Analysis of Thermal Comfort in an Office Environment With Underfloor Air Supply in a Tropical Climate. International Journal of Heating Ventilating Air Conditioning and Refrigerating Research, Atlanta, v. 12, n. 2, p. 215-229, 2006.

MUNDT, E. Non-Buoyant Pollutant Sources and Particles in Displacement Ventilation. Building and Environment, v. 36, n. 7, p. 829-836, 2001.

MUNDT, E. et al. Ventilation Effectiveness. Bélgica: Rehva, 2004. 74 p. (Guidebook n. 2).

OCCUPATIONAL SAFETY AND HEALTH ADMINISTRATION. Indoor Air Quality: schools. Disponível em: <http://www.osha.gov/SLTC/indoorairquality/scho ols.html>. Acesso em: 26 maio 2013.

PEREIRA, M. L. Medição, Predição e Análise de Partículas Aéreas em Salas Cirúrgicas. 196 f. São Paulo, 2008. Tese (Doutorado em Engenharia Civil) - Escola Politécnica, Universidade de São Paulo, São Paulo, 2008. 
SHIRAI, R.; BAUMAN, F.; ZAGREUS, L. First Post-Occupancy Evaluation (POE) of Block 225: capitol area east end complex. 2003. Disponível em:

<http://www.cbe.berkeley.edu/research/briefseastend.htm> Acesso em: 30 jul. 2013..

\section{WORLD HEALTH ORGANIZATION. WHO Air}

Quality Guidelines. 2006. Disponível em: <http://whqlibdoc.who.int/hq/2006/WHO_SDE_P HE_OEH_06.02_eng.pdf $>$. Acesso em: 23 maio 2013.

YUSOF, M. Z. M. et al. The Effectiveness of Underfloor Air Distribution (UFAD) System in Controlling Thermal Comfort and Indoor Air Quality. In: HEALTHY BUILDINGS:

CREATING A HEALTHY INDOOR

ENVIRONMENT FOR PEOPLE, 2006, Lisboa. Anais... Lisboa: IDMEC/FEUP, 2006. v. 2, p. 135140.

\section{Agradecimentos}

À Coordenação de Aperfeiçoamento de Pessoal de Nível Superior (Capes), pelo apoio financeiro à pesquisa.

À Fundação de Amparo à Pesquisa do Estado de São Paulo (Fapesp), pelo apoio financeiro à aquisição de alguns instrumentos de medição, bem como ao desenvolvimento do projeto Pipe Fapesp $n^{\circ} 07 / 59162-9$

\section{Renate Marè}

Departamento de Engenharia de Computação e Sistemas Digitais, Escola Politécnica | Universidade de São Paulo | Av. Prof. Luciano Gualberto, n. 158, trav. 3, Cidade Universitária | São Paulo - SP Brasil | CEP 05508-970 | Tel.: (+55) 113091.5262 |

E-mail: renatamare@gmail.com

Brenda Chaves Coelho Leite

Departamento de Engenharia de Construção Civil, Escola Politécnica | Universidade de São Paulo | Av. Prof. Almeida Prado, trav. 2, 83, Cidade Universitária | São Paulo - SP - Brasil | CEP 05508-900 | Tel.: (11) 3091-5284 | E-mail: brenda.leite@poli.usp.br

Revista Ambiente Construído

Associação Nacional de Tecnologia do Ambiente Construído

Av. Osvaldo Aranha, $99-3^{\circ}$ andar, Centro

Porto Alegre - RS - Brasil

CEP $90035-190$

Telefone: +55 (51) 3308-4084

Fax: +55 (51) 3308-4054

www.seer.ufrgs.br/ambienteconstruido

E-mail: ambienteconstruido@ufrgs.br 